\title{
Investigação sobre métodos em fatores humanos empregados na avaliação da interação idoso-embalagem
}

\section{Research on methods in human factors used to evaluate the interaction between elderly and packaging}

\author{
Bianca Marina Giordani ${ }^{1}$ \\ Flávio Anthero Nunes Vianna dos Santos ${ }^{2}$ \\ Milton José Cinelli ${ }^{3}$ \\ Marcelo Gitirana Gomes Ferreira ${ }^{4}$
}




\section{Resumo}

Em um mundo cada vez mais senil, compreender as capacidades dos idosos é fundamental nos projetos. Métodos em fatores humanos são uma forma confiável para compreender o usuário. Desse modo, o objetivo do presente estudo foi reunir procedimentos utilizados em pesquisas onde o foco é a relação entre idosos e embalagens, produtos comuns que nem sempre são manipulados com sucesso. Os métodos apresentados foram reunidos a partir de uma revisão de literatura. Os resultados mostram que são muitos os métodos utilizados, reforçando a complexidade da temática. Contudo, observa-se que os métodos são centrados em parâmetros pontuais como a força em detrimento de outros aspectos relevantes na interação.

Palavras-chave: Métodos; Fatores Humanos; Ergonomia; Idosos; Embalagens.

\section{Abstract}

In an increasingly senile world, understanding the elderly capabilities is fundamental in projects. Human factors methods are a reliable way to understand the user. Therefore, the aim of the present study was to group procedures used in research where the focus is the relationship between the elderly and packaging, common products that are not always successfully handled. The methods presented were gathered from a literature review. The results show that there are many methods used, reinforcing the complexity of the theme. However, it is observed that the methods are centered on parameters such as force to the detriment of other interaction relevant aspects.

Key-words: Methods; Human Factors; Ergonomics; Elderly; Packaging. 


\section{INTRODUÇÃO}

O aumento na parcela idosa da sociedade é um fato que tem impacto sobre as práticas e pesquisa em fatores humanos. Os idosos nunca foram tão numerosos quanto hoje e são um público em crescimento, a proporção de usuários senis de sistemas e produtos tem aumentando de forma constante. Desse modo, exige-se cada vez mais considerações específicas de design a fim de suprir a necessidade de tal público em usufruir de artefatos que sejam adequados para suas características e necessidades (BOOT et al., 2012).

Idosos não são mais uma minoria, mas sim um segmento expressivo da população. Assim, nas práticas projetuais, não se pode mais assumir que a maioria das pessoas é saudável e atlética, mas sim que muitos possuem limitações (KOSE, 2006). Por isso, as características do senescente devem ser compreendidas e inseridas nos projetos para garantir que esses usuários disponham de produtos seguros e eficientes (BOOT et al., 2012).

Uma forma de conhecer as particularidades da terceira idade, a fim de aplica-las ao processo de design, é por meio da utilização de métodos. Os métodos em fatores humanos são conjuntos de ferramentas de investigação utilizados para avaliar as características do usuário e do sistema, bem como as habilidades, limitações e necessidades. Métodos são cientificamente fundamentados, categorizados em pesquisas experimentais, estudos descritivos e pesquisas de avaliação (JACKO et al., 2012). Pesquisadores em fatores humanos fornecem informações sobre capacidades e limites humanos que designers podem utilizar no desenvolvimento conceitos (NEMETH, 2004).

Entendo a importância dos métodos e como eles podem contribuir para o desenvolvimento de projetos mais adequados, em especial para idosos, o presente estudo dedicou-se a reunir métodos que estão sendo utilizados e que tem como foco a interação entre idosos e artefatos. Os artefatos aqui observados são embalagens, visto que são produtos comuns no dia-a-dia, mas que nem sempre são manipulados com sucesso pela população senil (DUIZER; ROBERTSON; HAN, 2009).

Desse modo, a revisão sistemática de literatura realizada objetivou revisar, junto à literatura qualificada, pesquisas que utilizam métodos para avaliar a interação entre idoso e embalagens, a partir da perspectiva do manuseio e abertura das mesmas. Especificamente, buscou-se conhecer o delineamento dos estudos e quais os métodos por eles empregados para assim compreender o papel dos instrumentos e procedimentos utilizados no entendimento da problemática idoso-embalagem.

\subsection{Envelhecimento}

O aumento da expectativa de vida é um fenômeno que vem sendo observado na maior parte dos países. De 2000 a 2015, ela aumentou em 5 anos de modo global (WORLD HEALTH ORGANIZATION, 2016). Com isso, há um crescimento da parcela da população na terceira idade. Tal fenômeno é bastante relevante visto que o envelhecimento desencadeia transformações físicas no indivíduo, as quais refletem diretamente na relação dessas pessoas com os elementos que as cercam, restringindo as 
atividades que podem ou não ser realizadas pelo senescente, uma vez que a dimensão física está diretamente ligada com a maioria dos aspectos da vida diária, sendo um balizador para a qualidade de vida (SPIRDUSO, 2005).

As transformações físicas ocasionadas pelo envelhecimento recaem sobre todo o corpo humano, contudo, aquelas que afetam as mãos tem maior influência na realização das práticas do dia-a-dia, já que interferem na capacidade de manipular objetos (RANGANATHAN et al., 2001). Para Carmeli, Patish e Coleman (2003) a mão serve como uma importante ferramenta criativa, uma extensão do intelecto, um meio de comunicação não-verbal e um órgão sensível ao tato. A qualidade do desempenho de atividades diárias, relacionadas ao trabalho e recreativas são determinadas pela função manual. Pessoas idosas geralmente apresentam dificuldades com o funcionamento das mãos, em especial em atividades que requerem manejo fino.

\subsection{Relação Idoso-Embalagem}

Observa-se então que diversos dispositivos comuns não são projetados para as mãos idosas (CARMELI; PATISH; COLEMAN, 2003). São muitos os produtos que não atendem essa demanda, dentre eles as embalagens.

Dados do Inmetro (2016) mostram que 5,4\% dos acidentes de consumo que ocorrem no Brasil são ocasionados por embalagens. Estudos indicam que grande parte desses acidentes acontecem na abertura desses recipientes, sendo uma atividade potencialmente perigosa, em especial para idosos (CANER; PASCALL, 2010; ZUNJIC, 2011).

De acordo com Zunjic (2011), a maioria dos idosos já teve problemas na abertura de embalagens que ocasionaram ferimentos. Caner e Pascall (2010) corroboram com essa afirmação, no estudo promovido pelos autores foram identificadas queixas relacionadas com relação a embalagens, como a ocorrência de acidentes e lesões associadas à abertura, uso e disposição desses recipientes por parte dos usuários.

\subsection{Métodos em Fatores Humanos}

Uma preocupação primordial para os fatores humanos reside na capacidade de fazer generalizações e previsões sobre interações humanas para melhorar a produtividade, a segurança e a satisfação geral do usuário. Assim, os métodos desempenham um papel crítico na corroboração dessas generalizações e previsões. Sem métodos validados, as previsões e as generalizações seriam aproximadas ou infundadas (JACKO et al., 2012).

Os métodos são componente central na prática bem-sucedida de fatores humanos, são necessários para coletar dados sobre pessoas, desenvolver sistemas novos e aprimorados, avaliar o desempenho do sistema, avaliar demandas e efeitos do trabalho nas pessoas e entre outros (JACKO et al., 2012). A utilização de métodos é muito importante, pois eles oferecem estrutura aos testes e possuem caráter replicável (STANTON, 2006). 


\section{MÉTODOS}

O ponto de partida para esse estudo foi a realização de uma revisão sistemática de literatura. A revisão teve como objetivo analisar a literatura qualificada que trata sobre a temática e utiliza-se de métodos para avaliar a relação entre idosos e embalagens. Para isso, primeiramente foi estabelecido um protocolo contendo informações relevantes para a condução da pesquisa (Quadro 1).

\begin{tabular}{cl}
\hline & - Elderly; Old People; Old User; Elderly User; Older \\
& Adults; Ageing Consumer; Senescent; Senior. \\
Palavras-Chave & - Packaging; Package; Package Design; \\
& Consumer packaging. \\
& - Measurement; Evaluation; Assessment; \\
& Ergonomic Methods; Human Factors Methods. \\
\hline Fontes de busca & Scopus, ProQuest e Web of Science \\
\hline \multirow{2}{*}{ Critérios de inclusão } & - Artigos de periódicos acessíveis através \\
& do Portal de Periódicos da CAPES, Google \\
& Acadêmico ou portal das editoras, de forma \\
& gratuita. \\
& - Estudos escritos em Inglês, Português e \\
& Espanhol. \\
& - Estudos realizados nos últimos 10 anos. \\
\hline \multirow{2}{*}{ Estratégia de seleção } & Filtro 1: leitura de título, resumo e palavras-chave; \\
& Filtro 2: leitura completa dos artigos. \\
\hline
\end{tabular}

Quadro 1 - Resumo do protocolo da revisão sistemática de literatura.

Fonte: Os autores, 2018.

A partir do protocolo, realizou-se pesquisa nas bases de dados. Uma série de filtros foram realizados para a obtenção do portfólio final de referências. A síntese da busca e seleção de artigos pode ser visualizada na Tabela 1 e o portfólio final de referências encontra-se no Quadro 2.

\begin{tabular}{|c|c|c|c|c|c|c|}
\hline $\begin{array}{l}\text { Base de } \\
\text { Dados }\end{array}$ & Critérios e Filtros & $\begin{array}{l}\text { Busca } \\
\text { Inicial }\end{array}$ & Filtro 1 & $\begin{array}{c}\text { Filtro } 1 \\
\text { Resultado }\end{array}$ & Filtro 2 & $\begin{array}{c}\text { Portfólio } \\
\text { Final }\end{array}$ \\
\hline Scopus & $\begin{array}{l}\text { Critérios de inclusão; } \\
\text { Filtro por título, resumo, } \\
\text { palavras-chave; } \\
\text { Filtros por área; }\end{array}$ & 197 & 19 & \multirow{3}{*}{$34^{1}$} & \multirow{3}{*}{14} & \multirow{3}{*}{$16^{2}$} \\
\hline ProQuest & Critérios de inclusão; & 284 & 18 & & & \\
\hline $\begin{array}{l}\text { Web of } \\
\text { Science }\end{array}$ & $\begin{array}{l}\text { Critérios de inclusão; Filtro } \\
\text { por tópico e título; Filtros } \\
\text { por área; }\end{array}$ & 49 & 8 & & & \\
\hline
\end{tabular}

Tabela 1 - Síntese da busca e seleção de artigos.

Fonte: Os autores, 2018.

Soma do filtro um de todas as bases, removendo os trabalhos repetidos.

Composto por 14 artigos selecionados pela revisão sistemático e 2 externos. 


\begin{tabular}{|c|c|}
\hline & Referência \\
\hline 1 & $\begin{array}{l}\text { LEWIS, R. et al. Finger friction: Grip and opening packaging. Wear, v. 263, n. 7-12 SPEC. ISS., } \\
\text { p. 1124-1132, } 2007 .\end{array}$ \\
\hline 2 & $\begin{array}{l}\text { CARSE, B.; THOMSON, A.; STANSFIELD, B. Use of biomechanical data in the Inclusive Design } \\
\text { process: Packaging design and the older adult. Journal of Engineering Design, v. 21, n. 2-3, } \\
\text { p. } 289-303,2010 .\end{array}$ \\
\hline 3 & $\begin{array}{l}\text { YOXALL, A. et al. Squeezability. Part 2: getting stuff out of a bottle. Proceedings of the } \\
\text { Institution of Mechanical Engineers, v. 224, n. C6, p. 1261-1271, } 2010 .\end{array}$ \\
\hline 4 & $\begin{array}{l}\text { CARSE, B.; THOMSON, A.; STANSFIELD, B. A novel device for evaluating forces during the } \\
\text { dynamic jar opening action-Do older and younger adults do things differently? Medical } \\
\text { Engineering and Physics, v. 33, n. 4, p. 521-525, } 2011 \text {. }\end{array}$ \\
\hline 5 & $\begin{array}{l}\text { MARKS, M. et al. Packaging-A Problem for Patients with Hand Disorders? A Cross-sectional } \\
\text { Study on the Forces Applied to Packaging Tear Tabs. Journal of Hand Therapy, v. 25, n. 4, p. } \\
\text { 387-396, } 2012 \text {. }\end{array}$ \\
\hline 6 & $\begin{array}{l}\text { MÜHLFELD, L. et al. Influence of blister package design on usability among older adults. } \\
\text { International Journal of Clinical Pharmacy, v. 34, n. 4, p. 553-560, } 2012 .\end{array}$ \\
\hline 7 & $\begin{array}{l}\text { CANTY, L. A.; LEWIS, R.; YOXALL, A. Investigating openability of rigid plastic containers with } \\
\text { peelable lids: The link between human strength and grip and opening forces. Proceedings of } \\
\text { the Institution of Mechanical Engineers, Part C: Journal of Mechanical Engineering Science, } \\
\text { v. } 227, \text { n. 5, p. } 1056-1068,2013 \text {. }\end{array}$ \\
\hline 8 & $\begin{array}{l}\text { YEN, W.-T. et al. Preference of lid design characteristics by older adults with limited hand } \\
\text { function. Journal of Hand Therapy, v. 26, n. 3, p. 261-70; quiz 271, } 2013 .\end{array}$ \\
\hline 9 & $\begin{array}{l}\text { SORMUNEN, E.; NEVALA, N.; SIPILÄ, S. Critical factors in opening pharmaceutical packages: } \\
\text { A Usability study among healthcare workers, women with rheumatoid arthritis and elderly } \\
\text { women. Packaging Technology and Science, v. 27, n. 7, p. 559-576, } 2014 .\end{array}$ \\
\hline 10 & $\begin{array}{l}\text { HENSLER, S.; HERREN, D. B.; MARKS, M. New technical design of food packaging makes the } \\
\text { opening process easier for patients with hand disorders. Applied Ergonomics, v. 50, p. 1-7, } 2015 .\end{array}$ \\
\hline 11 & $\begin{array}{l}\text { BONFIM, G. H. C.; MEDOLA, F. O.; PASCHOARELLI, L. C. Correlation among cap design, } \\
\text { gripping technique and age in the opening of squeeze-and-turn packages: A biomechanical } \\
\text { study. International Journal of Industrial Ergonomics, v. 54, p. 178-183, } 2016 .\end{array}$ \\
\hline 12 & $\begin{array}{l}\text { BRAUN-MUNKER, M.; ECKER, F. Ease of opening of blistered solid dosage forms in a senior } \\
\text { citizens target group. International Journal of Pharmaceutics, v. 512, n. 2, SI, p. 412-415, } 2016 .\end{array}$ \\
\hline 13 & $\begin{array}{l}\text { BELL, A. F.; WALTON, K. L.; TAPSELL, L. C. Easy to open? Exploring the 'openability' of hospital } \\
\text { food and beverage packaging by older adults. Appetite, v. 98, p. 125-132, mar. } 2016 \text {. }\end{array}$ \\
\hline 14 & $\begin{array}{l}\text { YEN, W.-T. et al. Evaluation of jar lid design characteristics by older women with hand use } \\
\text { limitations. Applied Ergonomics, v. 52, p. 177, jan. } 2016 .\end{array}$ \\
\hline 15 & $\begin{array}{l}\text { WENK, S. et al. Evaluation of the Accessibility of Selected Packaging by Comparison of } \\
\text { Quantitative Measurements of the Opening Forces and Qualitative Surveys through Focus } \\
\text { Group Studies. Packaging Technology and Science, v. 29, n. 11, p. 559-570, } 2016 .\end{array}$ \\
\hline 16 & $\begin{array}{l}\text { BELL, A.; WALTON, K.; YOXALL, A. Measure for Measure: Pack Performance versus Human } \\
\text { Dexterity and Grip Strength. Packaging Technology and Science, v. 30, n. 4, p. 117-126, } 2017 .\end{array}$ \\
\hline
\end{tabular}

Quadro 2 - Artigos componentes do portfólio final da revisão sistemática. Fonte: Os autores, 2018.

\section{RESULTADOS}

\subsection{Análise de conteúdo}

Apesar dos estudos relacionarem embalagens com as capacidades físicas de idosos, cada trabalho abordou o tema sob uma perspectiva diferente. Desse modo, foi necessário conhecer como foram conduzidos para compreender de que modo os métodos neles descritos foram utilizados. 
O trabalho desenvolvido por Lewis et al. (2007) partiu da construção um dispositivo para medir o atrito dos dedos em relação a materiais utilizados em embalagens. Cálculos utilizando coeficientes de atrito e dados de força humana da literatura foram realizados para avaliar torques que podem ser aplicados por diferentes usuários na manipulação de embalagens. Os resultados dos cálculos foram validados por comparação com valores obtidos por torquimetro utilizados em frascos com tampa de rosca. Verificou-se então que mulheres idosas podem ter dificuldade em abrir embalagens desse tipo.

Carse, Thomson e Stansfield (2010) conduziram um estudo que investigou o uso de dados biomecânicos por designers como parte do processo de desenvolvimento de embalagens na indústria. Dados biomecânicos de idosos foram coletados e então apresentados aos designers para estabelecer o formato preferido para uso. A maioria dos formatos quantitativos de força e dados de movimento foram considerados inadequados para uso rotineiro devido a prioridades comerciais e falta de apreciação técnica. Por fim, os autores defenderam a importância do uso de testes biomecânicos na indústria com a finalidade de desenvolver embalagens mais inclusivas.

O estudo feito por Yoxall et al. (2010) procurou demonstrar as forças de preensão aplicadas ao apertar frascos e avaliou como essas forças mudam de acordo com sexo e idade, com a finalidade de analisar a capacidade do consumidor em obter conteúdo dos frascos. Cinco garrafas diferentes foram testadas com diferentes voluntários. Os resultados mostraram que mulheres e idosos desempenham forças menores na manipulação de tais embalagens.

Carse, Thomson e Stansfield (2011) apresentaram um novo dispositivo de medição usado para caracterizar forças manuais durante a abertura de embalagens. $O$ estudo mostrou que idosos tendem a aplicar as cargas na tampa lentamente e também promovem a abertura das embalagens em uma menor velocidade, indicando que eles se utilizam de uma estratégia de abertura mais cautelosa. Essas diferenças sugerem que um teste de torque simples não é suficiente para caracterizar as habilidades dos idosos em relação à abertura das embalagens.

A pesquisa conduzida por Marks et al. (2012) verificou que usuários com distúrbios nas mãos, algo recorrente na terceira idade, frequentemente tem dificuldade na abertura de embalagens com películas destacáveis, especialmente em função das forças envolvidas na tarefa. Para investigar esse fato, as forças foram simuladas em diferentes abas de embalagens a partir de um dispositivo. Os resultados demonstraram que maiores forças podem ser aplicadas em abas de alumínio longas, usando o movimento de pinça lateral. Contudo, foi constatado que pessoas com patologias nos membros superiores são capazes de atingir $53 \%$ da força exercida por pessoas saudáveis.

Mühlfeld et al. (2012) realizaram um estudo para identificar parâmetros de projeto que devem ser considerados ao desenvolver embalagens blister para fármacos destinados ao público idoso. Para isso, promoveram testes com voluntários utilizando diferentes embalagens. Os participantes foram questionados quanto a dificuldade, percepção da dor e avaliação geral do ato de abrir as embalagens. Concluiu-se que o design das embalagens blister, incluindo a força e o mecanismo de abertura, podem ter impacto significativo na usabilidade dessa embalagem, especialmente pelo público senil. 
A partir de pesquisas que sugerem que idosos têm dificuldades com embalagens fechadas com películas destacáveis (peelable), Canty, Lewis e Yoxall (2013) realizaram um estudo para entender os problemas com o acesso desses recipientes. Para isso, os autores criaram um dispositivo para medir as forças de remoção das películas, mensurando o atrito entre embalagem e dedo, e observaram usuários utilizando embalagens desse tipo. Os resultados indicaram que a força necessária para abrir os contêineres é menor do que as forças dos usuários medidos, incluindo pessoas idosas e, portanto, é provável que as questões relacionadas à acessibilidade da embalagem estejam relacionadas à destreza e não a força.

Yen et al. (2013) procuraram avaliar preferências em tampas de rosca, dentre atuais e novas concepções, com foco em pessoas que relataram dificuldade com a abertura de embalagens. Os testes foram realizados com idosas que possuem dores nas mãos. Os resultados obtidos com o estudo demonstraram que as preferências em relação as tampas são consistentes com as recomendações feitas por clínicos para aumentar a altura, o diâmetro, a textura e a forma dos frascos.

O estudo realizado por Sormunen, Nevala e Sipilä (2014) comparou a usabilidade de embalagens farmacêuticas para determinar os fatores críticos em invólucros com distintos mecanismos de abertura. Os testes foram realizados com enfermeiras, mulheres idosas e mulheres com artrite reumatoide. A usabilidade foi avaliada em relação à facilidade de abertura, tempo necessário para abrir a embalagem, atividade muscular (eletromiografia) e variações de movimento das extremidades superiores.

Em Hensler, Herren e Marks (2015) o objetivo foi investigar a possibilidade de produzir embalagens com películas destacáveis com abas de abertura (que armazenam queijos e derivados da carne) que sejam mais fáceis para usuários com distúrbios nas mãos, comuns na população idosa. Para isso, voluntários manipularam embalagens, comparando o modelo já comercializado e uma versão melhorada, e avaliaram a satisfação em utilizá-las. Os resultados da pesquisa mostraram que é possível desenvolver pacotes de alimentos fáceis de abrir que proporcionam maior satisfação ao consumidor.

O trabalho realizado por Bonfim, Medola e Paschoarelli (2016) buscou avaliar os efeitos do design da embalagem, da técnica de preensão e da idade do usuário no torque aplicado ao abrir embalagens. Foram analisadas embalagens de antisséptico bucal (tipo squeeze-and-turn), a partir das técnicas de preensão tridigital e bidigital com pessoas de diferentes idades. Os resultados mostram os fatores analisados tem influência direta no torque de abertura de tais embalagens.

Braun-Munker e Ecker (2016) trataram da influência da visibilidade e da mobilidade de medicamentos em blisters na abertura e satisfação do usuário. Foram realizados testes com participantes idosos promovendo a abertura dos blisters sem dispositivos auxiliares. Para mostrar a influência da visibilidade do comprimido no blister, as cápsulas foram embaladas em filmes transparentes e opacos. Observou-se influência moderada da visibilidade. Um segundo estudo abordou a mobilidade de das capsulas no blister. A movimentação limitada do comprimido na embalagem foi encontrada como critério principal na eficácia e efetividade da abertura, bem como na satisfação com o procedimento.

Bell, Walton e Tapsell (2016) abordaram a capacidade de idosos em abrir invó- 
lucros de alimentos utilizados em hospitais, objetivando obter informações sobre o papel da força da mão e dedos na abertura dos pacotes. Foram observados a abertura da embalagem e o tempo e assim foi determinada a correlação entre a força de preensão e pinça com os tempos de abertura. Os resultados foram consistentes com pesquisas anteriores, dando ênfase à conclusão de que embalagens de alimentos podem ser uma barreira para a nutrição adequada.

Yen et al. (2016) avaliaram características de design de tampas de embalagem (diâmetro, altura, forma superior, forma lateral e textura da superfície) por meio de testes com mulheres idosas que possuem limitações de função manual. Um processo de avaliação foi aplicado para examinar os principais efeitos das características do projeto da tampa sobre a usabilidade, determinadas pelas percepções de esforço e desconforto.

O estudo realizado por Wenk et al. (2016) determinou a relação da força para abrir embalagens de alimentos a partir de resultados de estudos com grupos focais realizados para conhecer as necessidades dos idosos com relação a esses produtos. Os resultados demonstraram que apenas parte da avaliação de uma embalagem depende da força de abertura, visto que a interação é influenciada por outros fatores de design e expectativas do consumidor, bem como experiências.

Bell, Walton e Yoxall (2017) demonstraram o papel da destreza na abertura de embalagens, em detrimento da força. A força de preensão, força de pinça e destreza foram medidas, bem como o tempo necessário para abrir alimentos hospitalares. De acordo com os autores, ao medir a destreza e as forças e comparar resultados contra o tempo para abrir uma embalagem, é possível fazer comparações da performance da embalagem e entender quais produtos são mais problemáticos.

\subsection{Análise dos métodos}

Os trabalhos mencionados utilizaram pesquisa empírica para obter seus resultados, para isso empregaram métodos, aliados a diferentes instrumentos e procedimentos. Dessa forma, pode-se identificar os mecanismos que proporcionaram a análise dos fatores humanos dos idosos e atributos de embalagens avaliados, a partir de seus diferentes enfoques. Uma síntese de tais métodos pode ser visualizada no Quadro 3.

Métodos

\begin{tabular}{|c|c|c|}
\hline \multirow{3}{*}{ 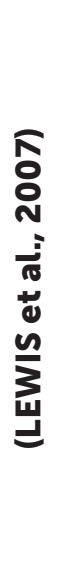 } & $\begin{array}{c}\text { Análise de atrito } \\
\text { dedo-material }\end{array}$ & $\begin{array}{l}\text { - Dispositivo fornece o coeficiente de atrito entre os dedos e materiais, em } \\
\text { diferentes condições de ambiente e utilização, a partir do deslizamento } \\
\text { do dedo sob o material. }\end{array}$ \\
\hline & $\begin{array}{l}\text { Teste de } \\
\text { bancada }\end{array}$ & $\begin{array}{l}\text { - Teste de atrito Bowden } \boldsymbol{\varepsilon} \text { Leben - Esse dispositivo é utilizado para } \\
\text { determinar o coeficiente de atrito entre materiais, como o corpo da } \\
\text { embalagem e a sua tampa, por exemplo. }\end{array}$ \\
\hline & $\begin{array}{c}\text { Medição do } \\
\text { máximo torque }\end{array}$ & $\begin{array}{l}\text { - Dados coletados durante o teste de atrito foram combinados a dados } \\
\text { descritos pela literatura e assim foram realizados cálculos de torque para } \\
\text { determinar a abertura de uma embalagem. } \\
\text { - Torquimetro - dispositivo internamente instalado na embalagem e } \\
\text { conectado a uma extensão anexada à tampa que avalia o torque humano } \\
\text { na abertura do objeto. }\end{array}$ \\
\hline
\end{tabular}




\begin{tabular}{|c|c|c|}
\hline \multirow{3}{*}{ 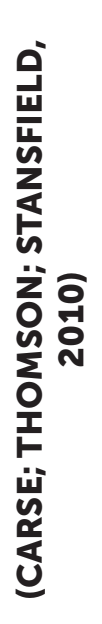 } & $\begin{array}{l}\text { Teste de } \\
\text { usabilidade }\end{array}$ & $\begin{array}{l}\text { - Foi requisitado a voluntários que manipulassem embalagens do } \\
\text { modo que geralmente fazem em ambiente doméstico. Enquanto eram } \\
\text { observados/gravados os participantes foram questionados sobre como } \\
\text { eles normalmente abririam cada tipo de embalagem. Posteriormente, eles } \\
\text { foram convidados a avaliar a dificuldade. Com isso, foi possível identificar } \\
\text { as embalagens mais difíceis, as estratégias de abertura e padrões de } \\
\text { movimento. }\end{array}$ \\
\hline & $\begin{array}{l}\text { Estudo de } \\
\text { movimento }\end{array}$ & $\begin{array}{l}\text { - Um sistema de análise de movimento foi usado para fornecer informações } \\
\text { sobre a localização do membro superior do sujeito no espaço durante a } \\
\text { tarefa de abertura da embalagem selecionada. }\end{array}$ \\
\hline & $\begin{array}{l}\text { Medição do } \\
\text { máximo torque } \\
\text { e outras forças }\end{array}$ & $\begin{array}{l}\text { - Dispositivo de simulação dinâmica - Um dispositivo simulação } \\
\text { dinâmica foi fabricado. Este dispositivo permitiu medir as forças de } \\
\text { preensão e torque na abertura da embalagem. }\end{array}$ \\
\hline \multirow{3}{*}{ 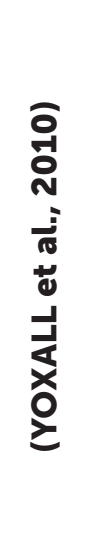 } & $\begin{array}{l}\text { Análise de força } \\
\text { manual e dos } \\
\quad \text { dedos }\end{array}$ & $\begin{array}{l}\text { - Software e sensores Tekscan - Utilizados para medir as forças ao } \\
\text { acessar o conteúdo de embalagens de apertar. O software permite a } \\
\text { análise da distribuição e concentração da força através da mão e dos } \\
\text { dedos ao apertar a garrafa. }\end{array}$ \\
\hline & $\begin{array}{l}\text { Teste de } \\
\text { usabilidade }\end{array}$ & $\begin{array}{l}\text { - Foi solicitado que os voluntários utilizassem as embalagens, apertando } \\
\text { e retirando o líquido contido nos recipientes. A quantidade de produto } \\
\text { expulsa em cada aperto foi medida por balanças. Os participantes foram } \\
\text { convidados a espremer a garrafa com seu estilo normal e a repetir o teste } \\
\text { usando outros estilos. }\end{array}$ \\
\hline & $\begin{array}{l}\text { Entrevista/ } \\
\text { Questionário }\end{array}$ & $\begin{array}{l}\text { - A idade, o gênero e outras informações foram coletadas juntamente } \\
\text { com entrevistas sobre a experiência do usuário em usar a embalagem. }\end{array}$ \\
\hline \multirow{4}{*}{ 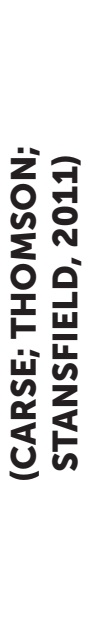 } & $\begin{array}{l}\text { Medição do } \\
\text { máximo torque } \\
\text { e outras forças }\end{array}$ & $\begin{array}{l}\text { - Dispositivo de simulação dinâmica - Um dispositivo simulação } \\
\text { dinâmica foi fabricado. Este dispositivo permitiu medir as forças de } \\
\text { preensão e torque na abertura da embalagem. }\end{array}$ \\
\hline & $\begin{array}{l}\text { Teste de } \\
\text { usabilidade }\end{array}$ & $\begin{array}{l}\text { - Os pesquisados foram convidados a colocar a embalagem na posição } \\
\text { preferida antes de abrir e posicionarem sua mão na tampa de modo } \\
\text { que o polegar ficasse em um dos dois segmentos da tampa e outros } \\
\text { dedos no segmento restante. A partir disso foram estimulados a abrir as } \\
\text { embalagens. }\end{array}$ \\
\hline & $\begin{array}{l}\text { Análise de força } \\
\quad \text { manual }\end{array}$ & - Dinamômetro Palmar - avaliação da força máxima de preensão palmar; \\
\hline & $\begin{array}{c}\text { Teste de } \\
\text { destreza manual }\end{array}$ & - Purdue Pegboard - avaliação da destreza manual. \\
\hline
\end{tabular}




\begin{tabular}{|c|c|c|}
\hline \multirow{3}{*}{ 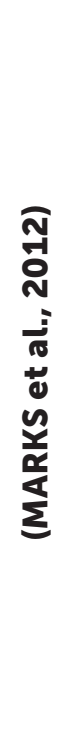 } & $\begin{array}{l}\text { Análise de força } \\
\quad \text { dos dedos }\end{array}$ & $\begin{array}{l}\text { - Pinch Pull Force Tester - Dispositivo criado para mensurar as forças } \\
\text { aplicadas por usuários na abertura de embalagens com abas. } \\
\text { - Dinamómetro - As forças máximas de pinça lateral e ponta-a-ponta } \\
\text { foram medidas com um medidor de preensão digital. }\end{array}$ \\
\hline & $\begin{array}{l}\text { Entrevistal } \\
\text { Questionário }\end{array}$ & $\begin{array}{l}\text { - Um questionário contendo imagens de embalagens com diferentes } \\
\text { mecanismos de abertura foi dado aos usuários. Eles foram convidados } \\
\text { a indicar se já tiveram dificuldades ao abri-las. As dificuldades foram } \\
\text { definidas como desconforto na abertura e/ou necessidade de um } \\
\text { dispositivo assistivo e/ou não possível abrir. } \\
\text { - Medida de Avaliação do Paciente (PEM) - Para avaliar a função subjetiva, } \\
\text { os usuários preencheram um questionário que fornece resultados sobre } \\
\text { distúrbios nas mãos. } \\
\text { - EuroQoL 5D (EQ5D) - utilizado para avaliar a qualidade de vida dos } \\
\text { participantes. }\end{array}$ \\
\hline & $\begin{array}{l}\text { Teste de } \\
\text { mobilidade }\end{array}$ & $\begin{array}{l}\text { - Índice de Kapandji - A amplitude de movimento da oposição do } \\
\text { polegar foi quantificada de acordo com o índice de Kapandji. }\end{array}$ \\
\hline \multirow{4}{*}{ 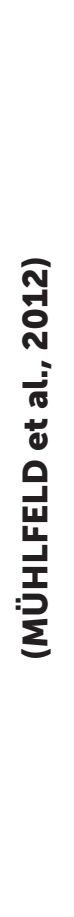 } & $\begin{array}{l}\text { Teste de } \\
\text { bancada }\end{array}$ & $\begin{array}{l}\text { - Máquina de ensaio LRX - o equipamento foi utilizado para analisar } \\
\text { as forças que são necessárias para abrir blisters, tanto para destacar as } \\
\text { películas, quanto para rompê-las. }\end{array}$ \\
\hline & $\begin{array}{l}\text { Entrevista/ } \\
\text { Questionário }\end{array}$ & $\begin{array}{l}\text { - Os dados sobre a situação de vida (independentes ou independentes, } \\
\text { com ajuda parcial de parentes ou serviços de enfermagem) e doenças } \\
\text { relevantes (reumatismo, acidente vascular cerebral, artrite, doença de } \\
\text { Parkinson) foram obtidos dos participantes. }\end{array}$ \\
\hline & Teste de visão & $\begin{array}{l}\text { - Teste de acuidade visual - foi utilizada uma folha de papel com duas } \\
\text { linhas de números em tamanhos diferentes. Pessoas capazes de ler Arial } \\
6 \text { foram classificadas como "++"; pessoas capazes de ler Arial } 12 \text { como } \\
\text { "+"; Todos os outros foram classificados como" - ". }\end{array}$ \\
\hline & $\begin{array}{l}\text { Teste de } \\
\text { usabilidade }\end{array}$ & $\begin{array}{l}\text { - Blisters foram entregues aos participantes e o mecanismo de abertura } \\
\text { foi explicado. Posteriormente, os participantes foram convidados a tirar } \\
4 \text { comprimidos do blister e o tempo foi gravado, sendo interrompido } \\
\text { após } 4 \text { min. Os participantes foram questionados sobre a dificuldade } \\
\text { em abrir o blister e se sentiam dor durante a abertura. Posteriormente, } \\
\text { foram solicitados uma avaliação geral do blister. Além disso, o número de } \\
\text { comprimidos removidos foi contado e gravado. Também, foi notado se } \\
\text { os participantes abandonaram a atividade antes do fim do tempo. }\end{array}$ \\
\hline \multirow{3}{*}{ 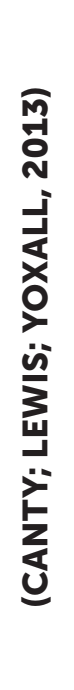 } & $\begin{array}{l}\text { Teste de } \\
\text { usabilidade }\end{array}$ & $\begin{array}{l}\text { - Participantes foram analisados para conhecimento de técnicas utilizadas } \\
\text { na abertura das embalagens estudadas. Foram feitos questionamentos em } \\
\text { relação a interação que as pessoas tiveram com a embalagem estudada, } \\
\text { tendo foco em como eles seguraram o pote, como eles localizaram a } \\
\text { aba e como ela foi agarrada, em que direção foi aplicada e se foram } \\
\text { encontrados problemas ao tentar abrir. }\end{array}$ \\
\hline & $\begin{array}{l}\text { Teste de } \\
\text { bancada }\end{array}$ & $\begin{array}{l}\text { - Plataforma/Teste hidráulico - A força para destacar as películas das } \\
\text { embalagens foi encontrada usando uma plataforma montada em uma } \\
\text { máquina de teste hidráulica. Um clipe é fixado na aba da película. Esse } \\
\text { clipe é anexado a um cabo, à medida que o cabo se aperta e move ao } \\
\text { redor de um rolo a aba é puxada para trás e a película é removida, isso } \\
\text { ocorre quando força de abertura foi alcançada. }\end{array}$ \\
\hline & $\begin{array}{l}\text { Análise de atrito } \\
\text { dedo-material }\end{array}$ & $\begin{array}{l}\text { - Dispositivo fornece o coeficiente de atrito entre os dedos e materiais, em } \\
\text { diferentes condições de ambiente e utilização, a partir do deslizamento } \\
\text { do dedo sob o material. }\end{array}$ \\
\hline
\end{tabular}




\begin{tabular}{|c|c|c|}
\hline \multirow{7}{*}{ 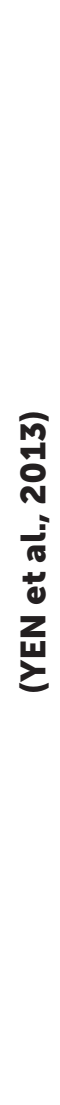 } & $\begin{array}{l}\text { Entrevista/ } \\
\text { Questionário }\end{array}$ & $\begin{array}{l}\text { - PROMIS HAQ e MHQ Pain -PROMIS HAQ identifica o nível de } \\
\text { dificuldade na realização de atividades da vida diária. A seção de Dor } \\
\text { do questionário MHQ Pain auxilia na identificação de presença de dor } \\
\text { crônica na mão e no pulso na semana anterior ao estudo. }\end{array}$ \\
\hline & $\begin{array}{c}\text { Teste de } \\
\text { destreza e } \\
\text { sensibilidade }\end{array}$ & $\begin{array}{l}\text { - Teste de extração de Moberg (MPUT) - O teste foi ministrado usando } \\
\text { doze objetos para medir limitações na destreza e sensibilidade. Os } \\
\text { indivíduos foram instruídos a retirar itens de um determinado local, cada } \\
\text { vez o mais rápido, e colocá-los em um recipiente ao lado. }\end{array}$ \\
\hline & $\begin{array}{l}\text { Análise de força } \\
\text { dos dedos }\end{array}$ & $\begin{array}{l}\text { - Dinamômetro Pinça - Utilizado para avaliar a força da pinça trípode } \\
\text { e lateral. }\end{array}$ \\
\hline & $\begin{array}{l}\text { Teste de } \\
\text { integridade do } \\
\text { polegar }\end{array}$ & $\begin{array}{l}\text { - A integridade anatômica da articulação metacarpofalângica do polegar } \\
\text { foi medida para estabelecer a estabilidade da articulação durante o } \\
\text { movimento de abertura de frascos. Esse parâmetro foi medido pois } \\
\text { contribui para limitar a capacidade de preensão nas tampas dos frascos. }\end{array}$ \\
\hline & $\begin{array}{l}\text { Teste de } \\
\text { mobilidade }\end{array}$ & $\begin{array}{l}\text { - Goniômetro - A mobilidade ativa foi medida utilizando medidas de } \\
\text { goniometria. }\end{array}$ \\
\hline & $\begin{array}{l}\text { Teste de } \\
\text { Usabilidade }\end{array}$ & $\begin{array}{l}\text { - Foi solicitado que os participantes interagissem com as embalagens e } \\
\text { tampas do estudo. }\end{array}$ \\
\hline & $\begin{array}{l}\text { Entrevista/ } \\
\text { Questionário }\end{array}$ & $\begin{array}{l}\text { - O formulário foi projetado para documentar sistematicamente as } \\
\text { preferências de cada participante no design de tampas. Para cada tampa, } \\
\text { o participante foi questionado sobre como se sentiam em relação ao } \\
\text { conforto, de acordo com características diferentes das tampas. }\end{array}$ \\
\hline \multirow{6}{*}{ 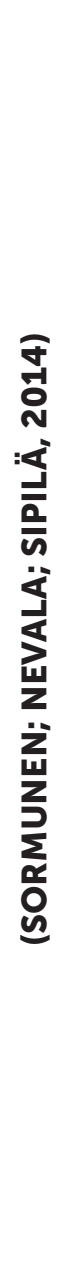 } & $\begin{array}{l}\text { Entrevista/ } \\
\text { Questionário }\end{array}$ & $\begin{array}{l}\text { - O questionário procurou determinar informações básicas sobre os } \\
\text { voluntários como idade, situação do trabalho, estado de saúde, uso } \\
\text { de medicamentos, dificuldades com o manuseio de embalagens, } \\
\text { possível necessidade de ajuda no manuseio e função física das mãos } \\
\text { nas atividades diárias. }\end{array}$ \\
\hline & $\begin{array}{l}\text { Análise de } \\
\text { dimensões, } \\
\text { força manual e } \\
\text { dos dedos }\end{array}$ & $\begin{array}{l}\text { - Medição das dimensões das mãos (fita métrica) - comprimento e } \\
\text { largura; } \\
\text { - Dinamômetro Palmar - avaliação da força de preensão palmar; } \\
\text { - Dinamômetro Pinça - para avaliar a força da pinça. }\end{array}$ \\
\hline & $\begin{array}{l}\text { Teste de } \\
\text { usabilidade }\end{array}$ & $\begin{array}{l}\text { - Baseado no European Committee for Standardization - O teste de } \\
\text { usabilidade exigiu que o participante realizasse uma tarefa com cada } \\
\text { uma das embalagens. A tarefa consistiu em abrir o recipiente, pegar a } \\
\text { quantidade pretendida e fecha-lo em } 1 \mathrm{~min} \text {. } \\
\text { - Avaliação baseado no Nordic 'Easy open pack' - A usabilidade percebida } \\
\text { foi avaliada em escala analógica visual. Os participantes foram convidados } \\
\text { a marcar o ponto na linha de } 100 \mathrm{~mm} \text { que indicava sua avaliação do recurso } \\
\text { em questão. }\end{array}$ \\
\hline & $\begin{array}{l}\text { Entrevista/ } \\
\text { Questionário }\end{array}$ & $\begin{array}{l}\text { - Após a conclusão da tarefa, o participante respondeu perguntas sobre } \\
\text { recursos de usabilidade (compreensão do mecanismo de abertura, } \\
\text { capacidade de preensão e manutenção da preensão na embalagem, } \\
\text { quebra da embalagem durante a abertura, facilidade de obtenção da dose } \\
\text { adequada de medicamento e avaliação geral da facilidade de abertura). }\end{array}$ \\
\hline & $\begin{array}{l}\text { Tensão } \\
\text { muscular }\end{array}$ & $\begin{array}{l}\text { - Eletromiografia - A tensão muscular no manuseio das embalagens foi } \\
\text { medida com eletromiografia de superfície dos extensores do punho e } \\
\text { flexores do pulso, bem como do flexor do polegar e região dos ombros. }\end{array}$ \\
\hline & $\begin{array}{l}\text { Teste de } \\
\text { mobilidade }\end{array}$ & $\begin{array}{l}\text { - Eletrogoniômetro e Torsiômetro - As distâncias de movimento das } \\
\text { mãos, punho e braço foram medidas. }\end{array}$ \\
\hline
\end{tabular}




\begin{tabular}{|c|c|c|}
\hline \multirow{3}{*}{ 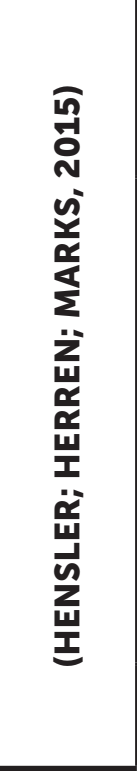 } & $\begin{array}{c}\text { Teste de } \\
\text { usabilidade }\end{array}$ & $\begin{array}{l}\text { - Foi solicitado que os idosos abrissem três embalagens. Todas embalagens } \\
\text { foram abertas da maneira usual e sem auxílio. O processo de abertura foi } \\
\text { filmado para que quaisquer dificuldades com a embalagem pudessem ser } \\
\text { avaliadas objetivamente. }\end{array}$ \\
\hline & $\begin{array}{c}\text { Entrevistal } \\
\text { Questionário }\end{array}$ & $\begin{array}{l}\text { - Questionário de satisfação - Para cada embalagem aberta os } \\
\text { participantes completaram um questionário sobre suas dificuldades na } \\
\text { abertura. O questionário incluiu um índice de satisfação do consumidor. } \\
\text { Este índice foi adaptado de um método aplicado em finanças, onde são } \\
\text { determinadas as expectativas gerais dos usuários com a embalagem e } \\
\text { a satisfação geral com o produto e suas características individuais. As } \\
\text { dificuldades percebidas durante o processo de abertura também foram } \\
\text { gravadas e classificadas. } \\
\text { - QuickDASH - Para registrar qualquer sintoma ou disfunção do membro } \\
\text { superior, os usuários completaram o questionário rápido de incapacidade } \\
\text { do braço, ombro e mão (quickDASH). }\end{array}$ \\
\hline & $\begin{array}{c}\text { Análise de força } \\
\text { dos dedos }\end{array}$ & - Dinamômetro Pinça - para avaliar a força da pinça. \\
\hline \multirow{2}{*}{ 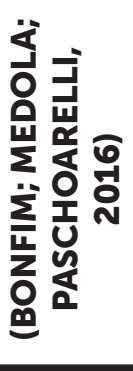 } & $\begin{array}{l}\text { Medição do } \\
\text { máximo torque }\end{array}$ & $\begin{array}{l}\text { - Torquimetro - internamente instalado na embalagem e conectado a } \\
\text { uma extensão anexada à tampa. As medidas de torque foram realizadas } \\
\text { para cada sujeito com três embalagens diferentes usando as técnicas de } \\
\text { preensão de dois e três dígitos. }\end{array}$ \\
\hline & $\begin{array}{c}\text { Teste de } \\
\text { usabilidade }\end{array}$ & $\begin{array}{l}\text { - As medidas de torque foram realizadas para cada sujeito com as três } \\
\text { embalagens usando duas técnicas de preensão. Os indivíduos foram } \\
\text { instruídos a segurar a embalagem na altura abdômen e girar a tampa com } \\
\text { a força máxima. }\end{array}$ \\
\hline 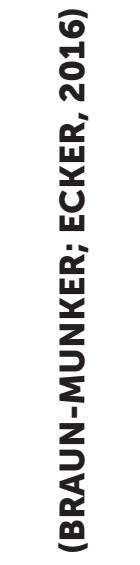 & $\begin{array}{c}\text { Teste de } \\
\text { usabilidade }\end{array}$ & $\begin{array}{l}\text { - CEN/TS } 15945 \text { (especificação técnica) - teste de três passos, analisando } \\
\text { eficiência, eficácia e satisfação do usuário no procedimento de abertura } \\
\text { de cada embalagem. } \\
\text { 1. Eficiência: dentro de } 5 \text { min, o usuário deve familiarizar-se com a } \\
\text { embalagem e seu mecanismo de abertura e posteriormente abri- } \\
\text { lo; } \\
\text { 2. Eficácia: uma segunda embalagem idêntica deve ser aberta em } \\
1 \text { min; } \\
\text { 3. Satisfação: a satisfação do paciente foi determinada em uma } \\
\text { escala de cinco passos variando de }+2 \text { (muito bom) a -2 (muito } \\
\text { ruim). } \\
\text { - A documentação em vídeo das mãos do participante foi registrada para } \\
\text { analisar os movimentos manuais durante o procedimento de abertura. }\end{array}$ \\
\hline \multirow{3}{*}{ 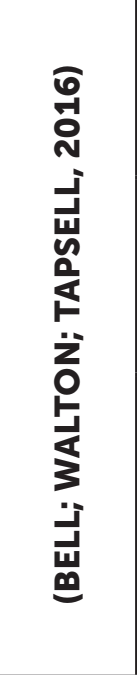 } & $\begin{array}{c}\text { Teste de } \\
\text { usabilidade }\end{array}$ & $\begin{array}{l}\text { - Um dispositivo de gravação foi utilizado para registrar as ações } \\
\text { dos participantes. Isso permitiu o registro do tempo da abertura das } \\
\text { embalagens, número de tentativas de abertura e quais estratégias usadas } \\
\text { para abrir a embalagem. }\end{array}$ \\
\hline & $\begin{array}{l}\text { Análise de força } \\
\text { manual e dos } \\
\quad \text { dedos }\end{array}$ & $\begin{array}{l}\text { - Dinamômetro Palmar - avaliação da força de preensão palmar; } \\
\text { - Dinamômetro Pinça - para avaliar a força da pinça polpa-a-polpa, } \\
\text { trípode e lateral. } \\
\text { (Protocolo padronizado pela American Society of Hand Therapists, 1992) }\end{array}$ \\
\hline & $\begin{array}{c}\text { Entrevista/ } \\
\text { Questionário }\end{array}$ & $\begin{array}{l}\text { - Foram realizadas perguntas relacionadas à função da mão (força, } \\
\text { tremor, dor, amplitude de movimento, condições artríticas, dominância } \\
\text { das mãos) e visão, bem como questões relacionadas à abertura das } \\
\text { embalagens. As classificações da capacidade de abertura foram } \\
\text { organizadas respondendo "sim" ou "não" seguido de uma escala de "sem } \\
\text { dificuldade / facilidade", "alguma dificuldade", "moderadamente difícil", } \\
\text { "muito difícil" e "impossível". }\end{array}$ \\
\hline
\end{tabular}




\begin{tabular}{|c|c|c|}
\hline \multirow{3}{*}{ 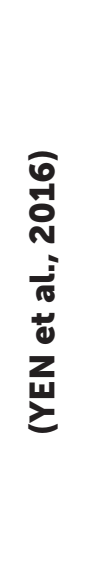 } & $\begin{array}{l}\text { Avaliação da } \\
\text { função manual* }\end{array}$ & $\begin{array}{l}\text { *Mesmo procedimento utilizado em Yen et al. (2013) - entrevista/ } \\
\text { questionário, análise de dimensões, força manual e dos dedos, tensão } \\
\text { muscular e teste de mobilidade. }\end{array}$ \\
\hline & $\begin{array}{l}\text { Medição de } \\
\text { máximo torque }\end{array}$ & $\begin{array}{l}\text { - Torquimetro - Dispositivo utilizado para avaliar o torque humano na } \\
\text { abertura de cada tampa. }\end{array}$ \\
\hline & $\begin{array}{l}\text { Teste de } \\
\text { usabilidade }\end{array}$ & $\begin{array}{l}\text { - Osciloscópio e Escala Borg CR10 - Toda vez que o usuário tentava abrir } \\
\text { a embalagem equipada com o torquimetro, um osciloscópio mostrava } \\
\text { os níveis de torque máximo, incentivando o participante a atingir níveis } \\
\text { maiores de força. Após cada teste, os participantes foram convidados a } \\
\text { avaliar a tampa que experimentaram, a partir da Escala Borg CR10 que foi } \\
\text { posicionada em frente ao participante, para ajudar os sujeitos a avaliar } \\
\text { seus esforços e desconforto. }\end{array}$ \\
\hline \multirow{3}{*}{ 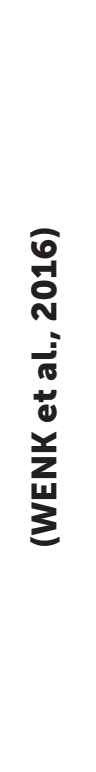 } & $\begin{array}{l}\text { Teste de } \\
\text { bancada }\end{array}$ & $\begin{array}{l}\text { - Teste de tração e Torquimetro - Forças de abertura de embalagens } \\
\text { foram determinadas utilizando uma máquina de teste de materiais. A } \\
\text { embalagem foi fixada com grampos e o processo de abertura foi simulado } \\
\text { através de um teste de tração. Os tipos de embalagem com rosca foram } \\
\text { medidas com um torquimetro digital. }\end{array}$ \\
\hline & $\begin{array}{l}\text { Teste de } \\
\text { Usabilidade }\end{array}$ & $\begin{array}{l}\text { - Grupos focais - Foram conduzidos em três países e tiveram como } \\
\text { objetivo discutir e ranquear embalagens. Os participantes foram } \\
\text { orientados quanto ao manuseio da embalagem, à identificação do } \\
\text { mecanismo de abertura, à descrição do procedimento de abertura e à } \\
\text { abertura real da embalagem. As embalagens mantiveram-se na frente } \\
\text { dos participantes na mesa durante as sessões do grupo para permitir o } \\
\text { ranking e a comparação de todos os diferentes sistemas de embalagens } \\
\text { de alimentos. }\end{array}$ \\
\hline & $\begin{array}{l}\text { Análise de força } \\
\text { manual e dos } \\
\quad \text { dedos }\end{array}$ & $\begin{array}{l}\text { - Sensor manual Pablo@ - O dispositivo multifuncional permitiu a } \\
\text { medição da força manual com vários tipos de preensão necessárias para } \\
\text { abrir embalagens. Preensão manual, força de pinça polpa-a-polpa e } \\
\text { pinça lateral foram medidas. }\end{array}$ \\
\hline \multirow{3}{*}{ 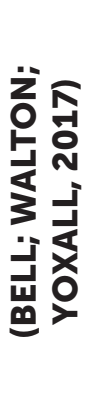 } & $\begin{array}{l}\text { Análise de força } \\
\text { manual e dos } \\
\quad \text { dedos }\end{array}$ & $\begin{array}{l}\text { - Dinamômetro Palmar - avaliação da força de preensão palmar; } \\
\text { - Dinamômetro Pinça - para avaliar a força da pinça polpa-a-polpa, } \\
\text { trípode e lateral. }\end{array}$ \\
\hline & $\begin{array}{c}\text { Teste de } \\
\text { destreza manual }\end{array}$ & - Purdue Pegboard - avaliação da destreza manual. \\
\hline & $\begin{array}{l}\text { Teste de } \\
\text { usabilidade }\end{array}$ & $\begin{array}{l}\text { - Os participantes foram convidados a abrir embalagens. Tempo e } \\
\text { tentativas foram registrados e posteriormente correlacionados como os } \\
\text { resultados do teste Purdue Pegboard. }\end{array}$ \\
\hline
\end{tabular}

Quadro 3 - Métodos de avaliação da interação idoso-embalagem utilizados nos estudos selecionados. Fonte: Os autores, 2018.

\section{DISCUSSÃO}

A partir da observação do Quadro 3, é possível conhecer e compreender os procedimentos usados durante a realização dos estudos selecionados pela revisão sistemática promovida, a partir da descrição dos autores.

Na Figura 1, pode-se observar uma síntese dos métodos apresentados com relação a sua objetividade/subjetividade e participação ou não do usuário idoso. Com isso, é possível verificar de que modo os procedimentos operam e que tipos de dados eles fornecem às pesquisas. 


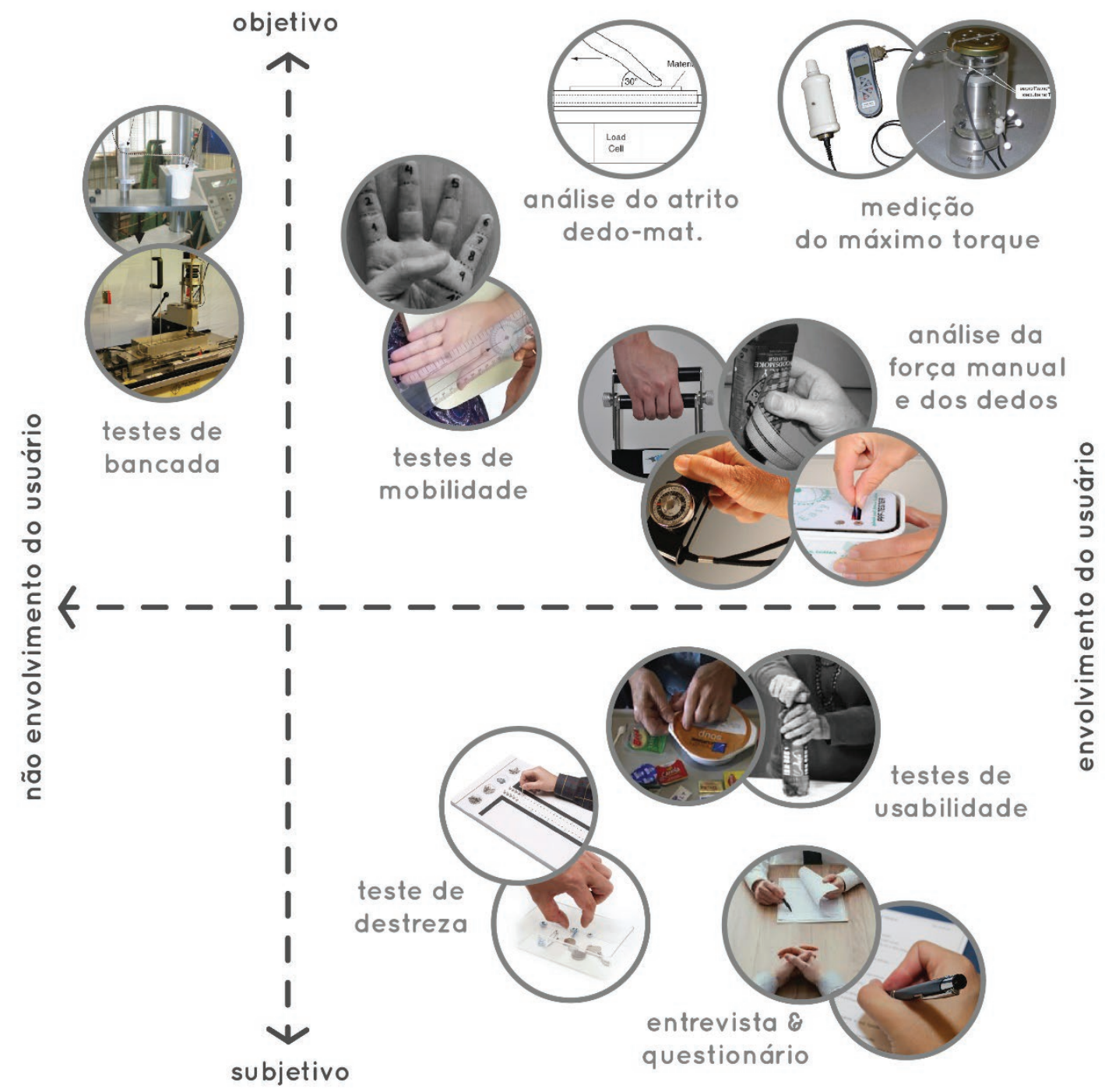

Figura 1 - Síntese dos métodos de acordo com objetividade/subjetividade e participação do usuário. Fonte: Elaborado pelos autores a partir dos estudos reunidos pela revisão sistemática, 2018.

A seguir, serão discutidos em maior profundidade os métodos que apareceram em mais de um trabalho, de acordo com suas diferentes abordagens e resultados.

Entrevista e Questionário. Recurso muito utilizado nos estudos. Esse método foi aplicado para compreender as características dos participantes dos experimentos, captar impressões sobre os testes de usabilidade com o produto, possíveis dificuldades ou mesmo a ocorrência de dores, além de conhecer a opinião sobre configurações de embalagens.

Dentre as entrevistas e questionários, um dos realizados por Yen et al. (2013) e posteriormente replicado em Yen et al. (2016), chama a atenção pela utilização de um questionário advindo da área da saúde. Vinte e sete itens do PROMIS HAQ auxiliaram na identificação do nível de dificuldade na realização de atividades da vida diária e cinco itens da seção de dor do questionário $M H Q$ Pain identificaram a presença de dor crônica na mão e no pulso na semana anterior ao estudo.

Da mesma forma, Marks et al. (2012) utilizaram o questionário de Medida de Avaliação do Paciente (PEM) para conhecer as patologias das mãos dos voluntários 
e o EuroQoL 5D (EQ5D), utilizado para avaliar a qualidade de vida dos participantes. Já Hensler, Herren e Marks (2015) aplicaram um questionário para registrar qualquer sintoma ou disfunção do membro superior, o questionário rápido de incapacidade do braço, ombro e mão (quickDASH).

A utilização de questionários advindos da área da saúde traz uma consistente contribuição à área dos fatores humanos, pois auxiliam de modo preciso a caracterizar os voluntários dos estudos. Esses questionamentos poder fornecer uma maior quantidade de informações sobre esse indivíduo, em especial sobre a sua saúde, algo muito importante nas pesquisas feitas com vulneráveis, que é o caso dos idosos.

Teste de usabilidade. A maior parte dos estudos utilizou-se de testes de usabilidade. Na maioria dos casos, o teste foi utilizado para identificar padrões de comportamento dos usuários durante a utilização das embalagens. A partir deles foi possível observar o modo com que acontece a interação usuário-embalagem, as diferentes estratégias de abertura, as ferramentas de auxilio que são empregadas em alguns casos, o sucesso ou dificuldade na abertura e entre outras coisas. Em vários trabalhos essa etapa foi registrada por vídeo ou foto para ser analisada posteriormente.

Apesar dos testes de usabilidade descritos terem sido bastante semelhantes, alguns deles se destacam por serem mais sistematizados ou procederem de acordo protocolos estabelecidos.

Em Mühlfeld et al. (2012), o teste de usabilidade foi bastante ordenado e cronometrado. Nesse estudo, os usuários tiveram que remover quatro comprimidos da embalagem em um tempo de quatro minutos (um minuto para cada comprimido). O tempo utilizado como base para sucesso da tarefa respeitou o recomendado pelo CFR 1700 (Code of Federal Regulations) dos Estados Unidos.

Já Sormunen, Nevala e Sipilä (2014) basearam o teste de usabilidade nas recomendações do European Committee for Standardization e no projeto Nordic "Easy open pack". Nesse caso, a tarefa consistiu em abrir os recipientes de medicamento, pegar a quantidade pretendida e fechar o recipiente em um minuto. Além disso, foi realizada uma avaliação da usabilidade percebida por meio da escala analógica visual.

Outro trabalho que obedeceu a uma sistemática em seu teste de usabilidade foi o realizado por Braun-Munker e Ecker (2016). Baseado na especificação técnica CEN/ TS 15945, o teste foi divido em três passos, analisando eficiência, eficácia e satisfação do usuário no procedimento de abertura de cada embalagem. A eficiência consistiu em dentro de cinco minutos, o usuário familiarizar-se com a embalagem e seu mecanismo de abertura para posteriormente abri-la. A eficácia compreendeu a abertura de uma segunda embalagem idêntica em um minuto. A satisfação do usuário foi determinada em uma escala de cinco passos variando de +2 (muito bom) a -2 (muito ruim).

O uso de protocolos já estabelecidos para os testes de usabilidade foi um aspecto muito interessante dessas pesquisas. A utilização deles aparenta fornecer maior credibilidade aos resultados dos estudos aos quais foram empregados, além de serem facilmente replicáveis.

Medição do máximo torque. Tal método foi utilizado por $1 / 3$ dos estudos. Isso se deve principalmente pelo tipo de embalagem investigada, frascos com tampa de rosca, que demandam a utilização de dispositivos que mensurem o torque empregado pelo ser humano na ação de abri-las, a fim de conhecer as forças empregadas. $O$ tor- 
quimetro foi uma constante nos estudos, porém não foi o único instrumento utilizado.

Lewis et al. (2007) calcularam o máximo torque a partir de equações que utilizaram dados da literatura e parâmetros adquiridos a partir de outros métodos, como o coeficiente de atrito. Dessa forma, os autores chegaram ao máximo torque de várias faixas etárias sem que esses usuários - em especial os idosos - participassem diretamente do estudo. Nesse caso, o torquimetro foi apenas utilizado por um voluntário para atestar a validade dos dados de torque humano previsto adquiridos por meio das avaliações e equações realizadas.

Nos trabalhos de Carse, Thomson e Stansfield $(2010 ; 2011)$ os autores desenvolveram um dispositivo de simulação dinâmica para obter o máximo toque e outras forças atuantes na tarefa de abrir tampas. Então, além de transdutores de torque, a tampa foi munida de dispositivos para medir outras forças envolvidas na ação.

No trabalho de Yen et al. (2016) o torquimetro foi utilizado juntamente com um osciloscópio. Quando o usuário estava tentando abrir a embalagem anexada ao torquimetro, o osciloscópio mostrava os níveis de torque máximo e o torque que estava sendo realizado no momento, incentivando o participante a atingir níveis maiores de força.

Os mecanismos utilizados até o momento para a medição do máximo torque vêm se mostrando bastante efetivos para a obtenção desse parâmetro. Contudo, os instrumentos ainda carecem de melhoria. A utilização de torquimetros na parte interna das embalagens implica em testes que não são totalmente realistas, visto que o conteúdo original das embalagens deve ser removido para a utilização da ferramenta e, em alguns casos, as tampas não chegam a abrir de fato, o que modifica as características da embalagem, tornando o experimento menos verossímil.

Análise de força manual e dos dedos. Mais da metade das pesquisas procuraram avaliar a força manual, dos dedos ou ambas. Para isso, a maioria dos estudos se valeu de instrumentos bastante populares como o dinamômetro palmar e o dinamômetro de pinça.

Contudo, alguns trabalhos fugiram a regra. O estudo realizado por Yoxall et al. (2010) promoveu tal análise por meio de sensores de força em filme, utilizados para medir as forças ao acessar o conteúdo de embalagens de apertar, como as de shampoo e maionese. A estratégia foi bastante interessante, visto que as forças de preensão foram adquiridas juntamente ao teste de usabilidade do produto. O software do produto também permitiu a análise da distribuição e concentração da força através da mão e dos dedos ao apertar a garrafa.

Os trabalhos de Carse, Thomson e Stansfield $(2010 ; 2011)$ também detectaram a força de preensão manual e dos dedos por meio do mesmo dispositivo que captou o torque empregado na ação de abrir a embalagem.

No estudo realizado por Marks et al. (2012), além do dinamômetro tradicional, um novo dispositivo foi criado para mensurar as forças aplicadas por usuários na abertura de embalagens com abas, o Pinch Pull Force Tester. O instrumento é capaz de medir a força feita no movimento de pinça quando uma aba é puxada para destacar uma película. Abas de diferentes tamanhos, perfis e materiais puderam ser simulados com essa ferramenta, além de diferentes movimentos de pinça.

No caso de Wenk et al. (2016) o dispositivo utilizado foi o sensor manual Pablo®, um dispositivo multifuncional computorizado que permitiu a medição da força manu- 
al com vários tipos de preensão necessárias para abrir os pacotes selecionados.

A análise de força manual e dos dedos foi um método muito relevante para os estudos, ainda mais quando se tratam de idosos. A utilização de equipamentos que promovem essa aferição é importante, pois eles ajudam a compreender as forças que podem ser desempenhadas pelos usuários e comparadas com aquelas que são necessárias para a manipulação de embalagens. O dinamômetro tradicional é um procedimento confiável para obtenção desses parâmetros, contudo, novos instrumentos, em especial aqueles que tem a capacidade de obter essas informações durante testes dinâmicos, são importantes, pois fornecem esses dados em situações reais.

Teste de bancada. Algumas simulações que foram realizadas em laboratório sem a presença do usuário. Esse método foi empregado por Lewis et al. (2007), Mühlfeld et al. (2012), Canty, Lewis e Yoxall (2013) e Wenk et al. (2016).

Em Lewis et al. (2007), um teste foi utilizado para determinar o coeficiente de atrito entre materiais, como o corpo da embalagem e a tampa, o que foi utilizado posteriormente no cálculo da forças necessárias para abertura da embalagem em questão. No trabalho de Mühlfeld et al. (2012), testes de bancada foram empregados para caracterizar as forças que são necessárias para abrir os blisters, tanto na ação de destacar películas, quanto para rompê-las no ato de expulsar o comprido da cavidade. No estudo de Canty, Lewis e Yoxall (2013) um ensaio também foi empregado para verificar as forças para destacar tampas dos recipientes de iogurte. Por fim, Wenk et al. (2016) utilizaram teste de tração e um torquimetro digital para determinar as forças de abertura de diferentes tipos de embalagens de alimentos.

Observa-se que na maioria dos estudos em que esse método esteve presente ele foi utilizado para determinar forças necessárias de abertura de embalagem para posteriormente serem comparadas com as que podem ser atendidas pelos seres humanos, em especial pelos idosos.

Teste de destreza manual. A avaliação da destreza manual de idosos foi abordada por quatro estudos, utilizando duas ferramentas distintas. A Purdue Pegboard foi utilizada nos trabalhos de Carse, Thomson e Stansfield (2011) e Bell, Walton e Yoxall (2017). O outro instrumento foi o teste de extração de Moberg (MPUT), utilizado por Yen et al. $(2013 ; 2016)$.

A maioria das pesquisas tem como foco as forças, contabilizar a destreza mostra como há um entendimento que essa questão também influencia no sucesso da interação do usuário com as embalagens. Nos resultados da pesquisa de Canty, Lewis e Yoxall (2013), os autores apontaram que a destreza pode vir a ser a principal barreira do idoso em relação a acessibilidade de embalagens com as iogurte (que necessitam a remoção de películas que fazem o fechamento do produto). Assim avaliar esse parâmetro nos estudos enriquece a avaliação e, em consequência, os resultados.

Teste de mobilidade. A avaliação da mobilidade dos membros superiores foi realizada por Marks et al. (2012), Yen et al. (2013; 2016) e Sormunen, Nevala e Sipilä (2014). Os testes foram realizados a partir da utilização de goniometros e torsiometros. Em apenas um trabalho foi utilizado o Índice de Kapandji, que aferiu a amplitude de movimento da oposição do polegar.

No caso de idosos, obter essa informação é algo relevante. Com a idade, existe uma limitação na amplitude dos movimentos dos membros superiores, então é 
possivel que isso influencie as atividades manuais desses sujeitos, como a interação com embalagens.

Análise de atrito dedo-material. Conhecer o coeficiente de atrito entre a pele humana e materiais foi uma estratégia utilizada por dois estudos (LEWIS et al., 2007 e CANTY; LEWIS; YOXALL, 2013). O mesmo equipamento e procedimento foram utilizados para realizar a aferição desse parâmetro, mas com foco em embalagens diferentes.

No estudo feito por Lewis et al. (2007), o coeficiente de atrito entre o dedo e os materiais da tampa foi realizado como meio para se prever o torque humano na abertura de embalagens com rosca. O coeficiente foi combinado com dados sobre as forças da mão humana e outros parâmetros e assim foi possível demonstrar a capacidade de abertura de diferentes faixas etárias, sexo, materiais e condições da embalagem.

Já no estudo de Canty, Lewis e Yoxall (2013) o coeficiente de atrito foi utilizado para calcular as forças envolvidas na abertura de embalagens fechadas com películas. Nesse caso, o coeficiente de atrito foi obtido para conhecer a sua influência na abertura. Da mesma forma que no estudo anterior, o coeficiente de atrito foi utilizado em equações que determinaram as forças de abertura para diferentes indivíduos, estimando o desempenho sem que eles necessariamente interagissem com a embalagem.

Com a utilização do coeficiente de atrito foi possível realizar a avaliação de forças na abertura sem que o usuário fosse exposto a tarefa em si. Isso se torna interessante no caso de idosos, uma vez que, em muitos casos, eles possuem patologias nas mãos e algumas atividades podem vir a ser bastante dolorosas. Com isso, é possível antecipar as forças necessárias para a abertura de uma embalagem de forma indireta, sem que o idoso ou o usuário em questão seja submetido ao procedimento real.

\section{CONSIDERAÇÕES FINAIS}

O presente estudo buscou investigar e analisar os métodos que vem sendo utilizados em pesquisas realizadas nos últimos dez anos (2007-2017) para tratar da interação de idosos e embalagens e com isso reuni-los em uma única publicação. $O$ trabalho partiu de uma revisão sistemática realizada com propósito de mapear, sistematizar, analisar e concentrar procedimentos e ferramentas utilizados para verificar problemas na relação entre pessoas senis e o desempenho de atividades manuais, como abertura e manipulação de embalagens.

Diversos métodos foram utilizados em cada um dos trabalhos analisados. Muitos métodos foram identificados em vários trabalhos, já outros foram exclusivos de certas abordagens tomadas por cada estudo. O volume e diversidade dos métodos reforça a complexidade da questão que envolve idosos e embalagens, não sendo algo que possa ser abarcado e tratado por apenas um método ou abordagem.

Com relação aos métodos, grande parte demonstrou serem bastante efetivos para a obtenção de resultados. Mesmo a partir de diferentes procedimentos e ferramentas, os trabalhos conseguiram mostrar que são pesquisas válidas e que contribuem de forma relevante para o conhecimento em torno desse tema.

Contudo, alguns métodos chamaram a atenção em detrimento de outros. A avaliação da destreza e o teste de mobilidade são alguns exemplos. Esses parâmetros foram pouco tratados nos trabalhos aqui apresentados, mesmo tendo influência na 
interação de idosos com embalagens. Percebe-se que o enfoque das pesquisas ainda é muito centrado em conhecer as forças deixando outros elementos em segundo plano. Os estudos que se preocuparam em empregar métodos centrados em destreza e mobilidade manual, por exemplo, em suas avaliações demonstram um entendimento que outros fatores atuam sobre a tarefa, não somente as forças. Assim, sugere-se para trabalhos futuros que outros fatores atuantes na interação sejam considerados.

Outro fato notável é tipo de embalagem avaliada em cada estudo. Na maioria dos casos, o foco foi dado para a interação com embalagens de alimentos, em especial a avaliação de frascos com tampa de rosca, popularmente utilizados para armazenar alimentos em conserva e geleia. Alguns trabalhos trataram de embalagens de medicamentos, mas com ênfase maior em blisters que armazenam comprimidos. Poucas pesquisas avaliaram embalagens do ramo higiene pessoal, perfumaria e cosméticos (HPPC) e produtos de limpeza. Assim, entende-se que a interação com embalagens de outros ramos, que não o alimentício e farmacêutico, ainda não foi amplamente tratada pelos estudos realizados, sendo uma oportunidade para pesquisas futuras, visto que esses produtos também são importantes para o dia-a-dia do idoso.

A partir do estudo realizado pode-se perceber a importância em conhecer os estudos que vêm sendo realizados sobre essa temática, notadamente os métodos e abordagens que são utilizados para tratar do tema, a fim de que possam ser ponderados em pesquisas futuras. As avaliações feitas nos artigos apresentados reforçam a relevância dos fatores humanos para adequação dos produtos aos usuários, principalmente a questão entre idosos e embalagens, no qual o modo de diagnosticar os problemas na interação é por meio de métodos.

\section{REFERÊNCIAS}

BELL, A. F.; WALTON, K. L.; TAPSELL, L. C. Easy to open? Exploring the 'openability' of hospital food and beverage packaging by older adults. Appetite, v. 98, p. 125-132, mar. 2016.

BELL, A.; WALTON, K.; YOXALL, A. Measure for Measure: Pack Performance versus Human Dexterity and Grip Strength. Packaging Technology and Science, v. 30, n. 4, p. 117-126, 2017.

BONFIM, G. H. C.; MEDOLA, F. O.; PASCHOARELLI, L. C. Correlation among cap design, gripping technique and age in the opening of squeeze-and-turn packages: A biomechanical study. International Journal of Industrial Ergonomics, v. 54, p. $178-183,2016$.

BOOT, W. R. et al. Design for Aging. In: SALVENDY, G. (Ed.). Handbook of Human Factors and Ergonomics. 4. ed. Hoboken, New Jersey: John Wiley \& Sons, 2012. p. 1442-1471.

BRAUN-MUNKER, M.; ECKER, F. Ease of opening of blistered solid dosage forms in a senior citizens target group. International Journal of Pharmaceutics, v. 512, n. 2, 
SI, p. 412-415, 2016.

CANER, C.; PASCALL, M. A. Consumer complaints and accidents related to food packaging. Packaging Technology and Science, v. 23, n. 7, p. 413-422, nov. 2010.

CANTY, L. A.; LEWIS, R.; YOXALL, A. Investigating openability of rigid plastic containers with peelable lids: The link between human strength and grip and opening forces. Proceedings of the Institution of Mechanical Engineers, Part C: Journal of Mechanical Engineering Science, v. 227, n. 5, p. 1056-1068, 2013.

CARMELI, E.; PATISH, H.; COLEMAN, R. The aging hand. Journals of Gerontology Series A Biological Sciences and Medical Sciences, v. 58, n. 2, p. 146-152, 2003.

CARSE, B.; THOMSON, A.; STANSFIELD, B. Use of biomechanical data in the Inclusive Design process: Packaging design and the older adult. Journal of Engineering Design, v. 21, n. 2-3, p. 289-303, 2010.

CARSE, B.; THOMSON, A.; STANSFIELD, B. A novel device for evaluating forces during the dynamic jar opening action-Do older and younger adults do things differently? Medical Engineering and Physics, v. 33, n. 4, p. 521-525, 2011.

DUIZER, L. M.; ROBERTSON, T.; HAN, J. Requirements for packaging from an ageing consumer's perspective. Packaging Technology and Science, v. 22, n. 4, p. 187-197, jun. 2009.

HENSLER, S.; HERREN, D. B.; MARKS, M. New technical design of food packaging makes the opening process easier for patients with hand disorders. Applied Ergonomics, v. 50, p. 1-7, 2015.

INMETRO. Sistema Inmetro de Monitoramento de Acidentes de Consumo. Disponível em: <http://www.inmetro.gov.br/consumidor/pdf/acidente-consumo-infografico-2016.pdf>. Acesso em: 7 nov. 2017.

JACKO, J. A. et al. Human Factors and Ergonomic Methods. In: SALVENDY, G. (Ed.). Handbook of Human Factors and Ergonomics. 4. ed. Hoboken, New Jersey: John Wiley \& Sons, Inc., 2012. p. 298-329.

KOSE, S. Universal Design for the Aging. In: KARWOWSKI, W. (Ed.). International Encyclopedia of Ergonomics and Human Factors. 2. ed. Boca Raton, FL: CRC Press, 2006. p. 227-230.

LEWIS, R. et al. Finger friction: Grip and opening packaging. Wear, v. 263, n. 7-12 SPEC. ISS., p. 1124-1132, 2007.

MARKS, M. et al. Packaging-A Problem for Patients with Hand Disorders? A Cros- 
s-sectional Study on the Forces Applied to Packaging Tear Tabs. Journal of Hand Therapy, v. 25, n. 4, p. 387-396, 2012.

MÜHLFELD, L. et al. Influence of blister package design on usability among older adults. International Journal of Clinical Pharmacy, v. 34, n. 4, p. 553-560, 2012.

NEMETH, C. P. Human Factors Methods for Design: Making Systems Human-Centered. Boca Raton, Florida: CRC Press, 2004.

RANGANATHAN, V. K. et al. Effects of aging on hand function. Journal of the American Geriatrics Society, v. 49, n. 11, p. 1478-1484, 2001.

SORMUNEN, E.; NEVALA, N.; SIPILÄ, S. Critical factors in opening pharmaceutical packages: A Usability study among healthcare workers, women with rheumatoid arthritis and elderly women. Packaging Technology and Science, v. 27, n. 7, p. 559576, 2014.

SPIRDUSO, W. W. Dimensões Físicas do Envelhecimento. Barueri, SP: Manole, 2005.

STANTON, N. Human Factors and Ergonomics Methods. In: KARWOWSKI, W. (Ed.). International Encyclopedia of Ergonomics and Human Factors. Boca Raton, Florida: CRC Press, 2006. p. 3197-3202.

WENK, S. et al. Evaluation of the Accessibility of Selected Packaging by Comparison of Quantitative Measurements of the Opening Forces and Qualitative Surveys through Focus Group Studies. Packaging Technology and Science, v. 29, n. 11, p. $559-570,2016$.

WORLD HEALTH ORGANIZATION. World health statistics 2016: monitoring health for the SDGs, sustainable development goals. Geneva: WHO Library Cataloguing -in-Publication Data, 2016.

YEN, W.-T. et al. Preference of lid design characteristics by older adults with limited hand function. Journal of Hand Therapy, v. 26, n. 3, p. 261-70; quiz 271, 2013.

YEN, W.-T. et al. Evaluation of jar lid design characteristics by older women with hand use limitations. Applied Ergonomics, v. 52, p. 177, jan. 2016.

YOXALL, A. et al. Squeezability. Part 2: getting stuff out of a bottle. Proceedings of the Institution of Mechanical Engineers, v. 224, n. C6, p. 1261-1271, 2010.

ZUNJIC, A. Ergonomics of Packaging. In: KARWOWSKI, W.; SOARES, M. M.; STANTON, N. A. (Eds.). Human Factors and Ergonomics in Consumer Product Design: Uses and Applications. Boca Raton, FL: CRC Press, 2011. p. 101-123. 